\section{A comparison of two doses of epidural fentanyl during Caesarean section}

Irvan Yee MD FRCPC, Jan Carstoniu MD FRCPC, Stephen Halpern MD FRCPC, Richard Pittini MD

\begin{abstract}
A prospective, randomized, double-blind study was performed to compare the analgesic efficacy and side effects of epidural fentanyl, $25 \mu \mathrm{g}$ vs $50 \mu \mathrm{g}$, when used to supplement epidural anaesthesia for elective Caesarean section. Fifiy ASA I and II patients were randomized into two groups: Group $I(n=24)$ received $25 \mu \mathrm{g}$ and Group $I I(n=26)$ received $50 \mu g$ of epidural fentanyl after the epidural test dose. No differences between the two groups were found on any measures of intraoperative pain, nausea, drowsiness, respiratory depression, hypotension, pruritus and neonatal outcome. The low levels of pain experienced by patients indicates that doses higher than $50 \mu \mathrm{g}$ of epidural fentanyl are usually unnecessary for optimal analgesia.
\end{abstract}

Une étude prospective en double-aveugle et randomisée a été conduite pour comparer l'efficacité analgésique et les effets secondaires du fentanyl en péridurale, $25 \mu \mathrm{g}$ vs $50 \mu \mathrm{g}$. Le fentanyl est utilisé comme complément d'une anesthésie péridurale pour césarienne élective. Cinquante patientes ASA I and II ont été réparties de façon randomisée en deux groupes: le groupe I $(n=24)$ a reçu $25 \mu \mathrm{g}$ de fentanyl et le groupe $I I(n=26)$ $50 \mu \mathrm{g}$ de fentanyl, injecté en péridurale après la dose test dans les deux groupes. Aucune différence entre les deux groupes n'a pu être mise en évidence concernant la douleur péri-opératoire, les nausées, la somnolence, la dépression respiratoire, l'hypotension, le prurit et les scores néonataux. Par ailleurs, les douleurs ressenties par les patientes étaient de faible importance, ceci montre que des doses supérieures à $50 \mu \mathrm{g}$ de fentanyl sont le plus souvent non nécessaires pour l'obtention d'une analgésie optimale.

\section{Key words}

ANAESTHESIA: obstetric;

ANAESTHETIC TECHNIQUES: epidural;

ANALGESICS: fentanyl;

PREGNANCY: Caesarean section.

From the Department of Anaesthesia, Women's College

Hospital and University of Toronto, Toronto, Ontario.

Address correspondence to: Dr. S. Halpern, Department of

Anaesthesia, Women's College Hospital, 76 Grenville Street,

Toronto, Ontario M5S 1B2.

Accepted for publication 26th April, 1993.
Incomplete anaesthesia may occur during Caesarean section under epidural blockade. However, several studies have shown considerable improvements in intraoperative analgesia and patient satisfaction when narcotics such as epidural fentanyl, $50-100 \mu \mathrm{g}$, are added to the local anaesthetic. ${ }^{1-7}$ Although the safety of such doses to both mother and neonate has been well substantiated, side effects such as drowsiness and nausea may occur. ${ }^{5}$ Another side effect of epidural narcotics, respiratory depression, has also been reported in obstetrical patients receiving epidural fentanyl $100 \mu \mathrm{g}^{6,8}$ and epidural meperidine 75 mg for Caesarean section. ${ }^{9}$ The present study was undertaken to examine whether a lower dose of epidural fentanyl, $25 \mu \mathrm{g}$, would compare favourably to $50 \mu \mathrm{g}$ in terms of analgesia and side effects and thus potentially provide a greater margin of safety.

\section{Methods}

Hospital Research Ethics Board approval and written, informed consent were obtained before entry of subjects into the study. Subjects were included if they were ASA class I or II, had uncomplicated term pregnancies, and were scheduled for elective Caesarean section under epidural anaesthesia. Staff from the hospital pharmacy used a random number table to assign 54 patients to two groups. Patients in Group I $(n=27)$ received epidural fentanyl $25 \mu \mathrm{g}$, while those in Group II $(n=27)$ received $50 \mu \mathrm{g}$. Demographic data, including maternal height, weight, age and whether or not this was a repeat Caesarean section were recorded on entry to the study by a research assistant blinded to the experimental conditions. This same person recorded all data in this study.

Anaesthetic technique was standardized in the two groups and the attending anaesthetist was also blinded to the experimental conditions. All patients were prehydrated with at least $1000 \mathrm{ml}$ Ringer's lactate. Epidural catheters were inserted at the $\mathrm{L}_{2,3}$ or $\mathrm{L}_{3,4}$ interspace using loss-of-resistance to air. Carbonated lidocaine $2 \%$ with 1:200,000 epinephrine was used for all patients. After a $3 \mathrm{ml}$ test dose of local anaesthetic, each patient was given $1 \mathrm{ml}$ of the study drug in a double-blind manner. The time of the test dose was recorded and was considered 
to be the induction time. The study drugs were prepared by hospital pharmacy staff in identical vials at a concentration of either $25 \mu \mathrm{g} \cdot \mathrm{ml}^{-1}$ or $50 \mu \mathrm{g} \cdot \mathrm{ml}^{-1}$. The local anaesthetic was then titrated in increments of five $\mathrm{ml}$ every three minutes by the anaesthetist until a $\mathrm{T}_{4}$ sensory block was achieved. The total dose and volume of lidocaine was recorded. All patients were positioned with left uterine displacement and given supplemental oxygen. Monitors included an automated blood pressure cuff, ECG, pulse oximeter and a capnometer attached to nasal prongs to measure respiratory rate.

The surgical variables recorded included inductiondelivery interval (time from injection of the test dose to delivery), uterine incision-delivery interval, total operative time and fetal presentation. Exteriorization of the uterus was at the discretion of the obstetrician; the incidence in the two groups was noted.

The quality of analgesia was assessed in three ways:

1 The number of patients requiring supplemental iv fentanyl in each group was recorded.

2 A visual analogue scale (VAS) was used to rate intraoperative pain at four specific times: skin incision, parietal peritoneal incision, delivery, and visceral peritoneal closure.

3 The patient's overall pain experience was assessed immediately postoperatively using the Short-Form McGill Pain Questionnaire (SF-MPQ). ${ }^{10}$

Baseline blood pressure and respiratory rate were recorded at the start of each case. Any decrease in mean arterial pressure $>20 \%$ of baseline and any decrease in respiratory rate to $<12$ per minute was recorded as hypotension and respiratory depression respectively. Otherwise the lowest blood pressure and respiratory rate achieved following induction of anaesthesia were noted. The dose of ephedrine (if any) administered by the anaesthetist was also recorded.

Patients were asked to rate their nausea and pruritus using a four-point scale $(0=$ none, $1=$ mild, $2=\bmod -$ erate, $3=$ severe) at skin incision and $30 \mathrm{~min}$ after this. Drowsiness was also evaluated on a four-point scale ( 0 $=$ none, $1=$ drowsy on direct questioning, $2=$ spontaneous complaint of drowsiness, $3=$ asleep).

The neonates were assessed using birth weight, 1 and 5 min Apgar scores and umbilical cord blood gases.

Demographic data, surgical variables, total lidocaine dose and volume, SF-MPQ scores, maternal blood pressure changes, lowest respiratory rate, birth weight and umbilical cord gas data were analyzed using the unpaired Student's $t$ test. The Mann-Whitney $U$ test was used to compare the groups in terms of VAS scores, ephedrine dose, maternal side effects and Apgar scores. Differences between groups in incidences of $i v$ analgesia supplementation, repeat Caesarean section, number of hypotensive
TABLE I Demographic data

\begin{tabular}{lcc}
\hline & Group \\
\cline { 2 - 3 } & $25 \mu g$ & $50 \mu g$ \\
\hline$n$ & 24 & 26 \\
Mean age (yr) & $32.17(0.73)^{*}$ & $32.73(0.99)$ \\
Mean height $(\mathrm{cm})$ & $161.17(1.7)$ & $161.58(1.6)$ \\
Mean weight $(\mathrm{kg})$ & $78.5(2.7)$ & $79.0(3.1)$ \\
Repeat CS $(n)$ & 19 & 15 \\
\hline
\end{tabular}

*Numbers in brackets represent standard error of the mean.

No differences were found between groups.

episodes, uterine exteriorization and fetal presentation were analyzed using chi square or Fisher's exact test as appropriate. A $P$ value of $<0.05$ was considered significant.

The sample size was determined using data from Tessler et al. ${ }^{4}$ where quality of analgesia was measured by recording the use of supplemental $i v$ fentanyl in patients undergoing Caesarean section using epidural anaesthesia. Calculations were thus based on the following assumptions:

1 approximately $50 \%$ of patients in Group I would require supplemental fentanyl;

2 approximately $15 \%$ of patients in Group II would require supplemental fentanyl.

According to the above a sample size of 54 patients would give a power of 0.8 at an alpha of 0.05 .

\section{Results}

Four patients were excluded from the data analysis because of failure to achieve adequate blockade $(n=2)$ (both patients achieved less than a $T_{12}$ level) or failure to follow the study protocol $(n=2)$. The patients who failed to reach adequate blockade required general anaesthesia and were considered failed epidurals. There were no differences between groups in demographic and surgical parameters (Tables I and II). There was no difference in local anaesthetic requirements between groups (Table II).

There were no differences between groups on any of the pain measures used. VAS scores are presented in Figure 1. Only one patient (in the $25 \mu \mathrm{g}$ group) had any pain at all (VAS $=2.5$ ) on skin incision. In fact all the VAS scores were low throughout the study. The SF-MPQ scores were also low: mean $=7.3$ and 7.1 for the 25 and $50 \mu \mathrm{g}$ groups respectively, out of a possible top score of 45. A post-hoc power analysis on the SF-MPQ data was performed. This study has a power of 0.8 to detect a three unit difference in score between groups (alpha $=0.05$ ). Intravenous fentanyl was given by the anaesthetist five and two times to the 25 and $50 \mu \mathrm{g}$ groups respectively (NS). 
TABLE II Surgical variables

\begin{tabular}{lll}
\hline & \multicolumn{2}{l}{ Group } \\
\cline { 2 - 3 } & $25 \mu \mathrm{g}$ & $50 \mu \mathrm{g}$ \\
\hline Mean uterine incision - delivery time (sec) & $144(11)^{*}$ & $133(11)$ \\
Mean induction - delivery time (min) & $34.1(2.1)$ & $38.3(2.2)$ \\
Mean total operative time (min) & $67.2(4.3)$ & $72.2(2.5)$ \\
Vertex presentations $(n)$ & 15 & 20 \\
Uterine exteriorizations $(n)$ & 5 & 9 \\
Mean total lidocaine dose $(\mathrm{ml})$ & $22.3(0.9)$ & $23.0(1.1)$ \\
\hline
\end{tabular}

*Numbers in brackets represent standard error of the mean.

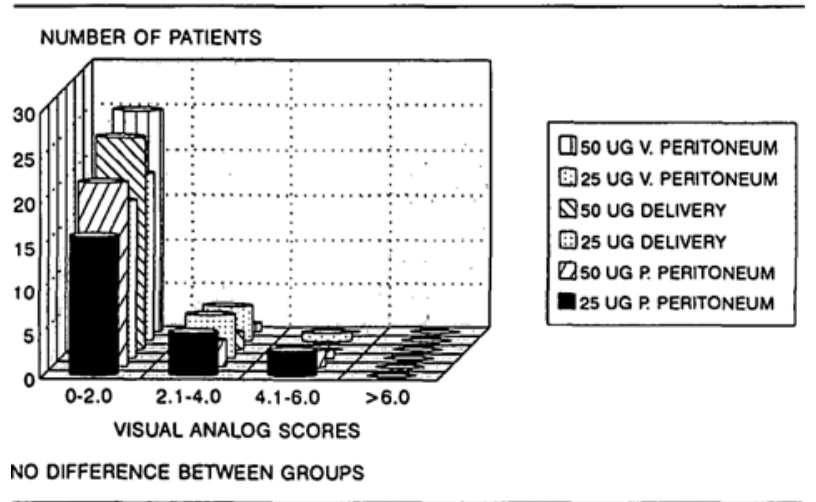

FIGURE 1 Visual analog pain scores.

No patients had intraoperative pruritus or respiratory depression. Mean changes in blood pressure (difference between baseline and lowest BP recorded), lowest respiratory rates recorded, nausea, drowsiness and number of hypotensive episodes were the same for both groups. It is worth noting that the scores for nausea and drowsiness were quite low and did not require intervention by the anaesthetist (Figure 2).

There were no adverse neonatal outcomes in this study. Birth weights, Apgar scores and umbilical cord gas values were the same regardless of epidural fentanyl dose (Table III).

\section{Discussion}

This study failed to show any differences in analgesic efficacy and incidence of side effects following $25 \mu \mathrm{g}$ or $50 \mu \mathrm{g}$ of epidurally administered fentanyl to women undergoing elective Caesarean section. Patients in the two study groups were well matched in terms of demographic data, dose and volume of local anaesthetic used and surgical factors such as duration of the operation and uterine exteriorization. All neonates did well.

A literature review shows that previous studies ${ }^{1-7}$ investigating epidural fentanyl during Caesarean section under epidural anaesthesia were all well designed in terms of appropriate randomization, controls, matching of

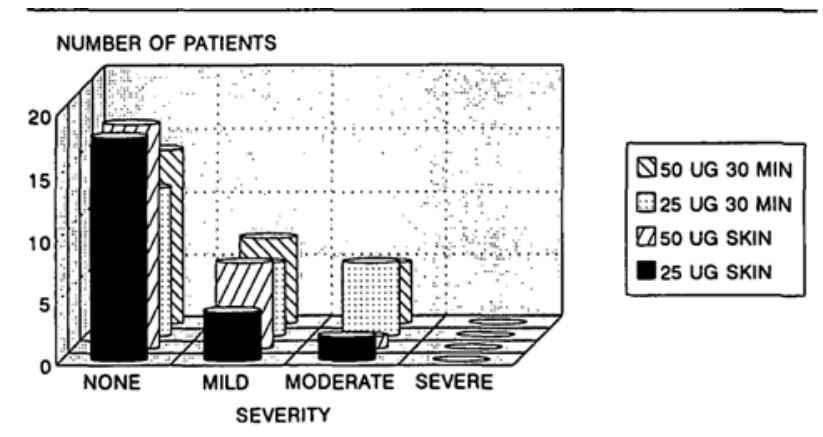

NO DIFFERENCE BETWEEN GROUPS

FIGURE 2A Drowsiness scores at skin incision and at skin incision $+30 \mathrm{~min}$

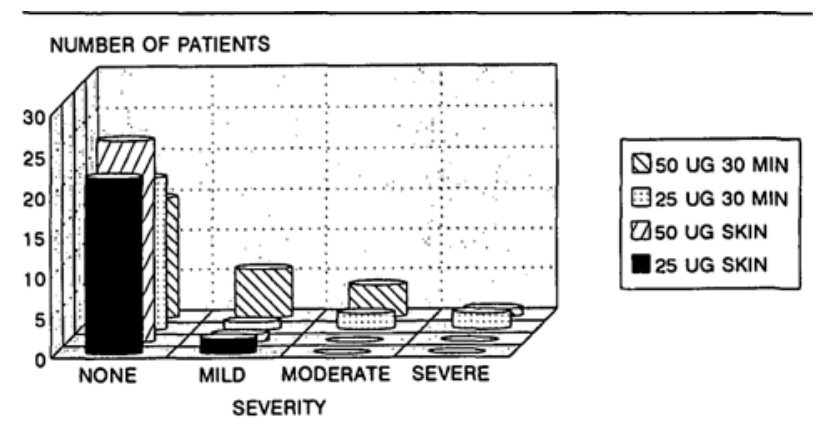

NO DIFFERENCE BETWEEN GROUPS

FIGURE 2B Nausea scores at skin incision and at skin incision $+30 \mathrm{~min}$.

TABLE III Neonatal outcome

\begin{tabular}{ccc}
\hline & \multicolumn{2}{l}{ Group } \\
\cline { 2 - 3 } & $25 \mu g$ & $50 \mu g$ \\
\hline Arterial $\mathrm{pH}^{*}$ & $7.28(0.01) \dagger$ & $7.29(0.01)$ \\
$\mathrm{pCO}_{2}$ & $56.6(1.9)$ & $55.2(1.2)$ \\
$\mathrm{pO}_{2}$ & $16.1(1.3)$ & $19.4(2.1)$ \\
Venous $\mathrm{pH}$ & $7.35(0.01)$ & $7.36(0.01)$ \\
$\mathrm{pCO}_{2}$ & $44.9(1.2)$ & $44.9(0.08)$ \\
$\mathrm{pO}_{2}$ & $30.4(1.5)$ & $30.3(1.2)$ \\
1 min APGAR + & 9 & 9 \\
5 min APGAR & 9 & 9 \\
Birth weight (gm) & $3566(95)$ & $3494(132)$ \\
\hline
\end{tabular}

*Blood gas and birth weight data represent mean values.

†Numbers in brackets represent standard error of the mean.

†APGAR data represent median values.

No differences were found between groups.

groups and blinding of subjects and investigators. Different local anaesthetic solutions have been used: bupivacaine $0.5 \%$ with and without epinephrine, ${ }^{1-3,6}$ bupivacaine $0.75 \%,{ }^{7}$ lidocaine $2 \%$ with epinephrine ${ }^{4-5}$ and fentanyl doses ranged from 50-100 $\mu \mathrm{g}$ in all but one study. ${ }^{7}$ Methods of assessing the quality of analgesia also varied: VAS scores, ${ }^{2,6,7}$ four-point pain scales with ratings made 
by the patient and/or investigator ${ }^{26}$ and the need for supplemental iv narcotics intraoperatively ${ }^{1,2,4}$ have all been used. Despite the possible lack of sensitivity of some of these measures, particularly four-point scales, all these studies strongly supported the notion that epidural fentanyl improves the quality of analgesia during Caesarean section under epidural anaesthesia. For this reason a placebo control group was not included in this study.

Furthermore, an effort was made in this study to maximize the sensitivity of pain outcome measures by assessing pain in three different ways. The VAS scores have been used for years in pain research and have proved themselves to be sensitive, reliable and valid indicators of change in the immediate sensory experience of pain. " However, pain is a complex subjective experience that involves more than simple sensory pathways. It includes affective and cognitive factors as well. This may be of particular importance in an emotion-laden experience such as birth. The SF-MPQ was designed to account for these factors and has also been reported to be sensitive, reliable and valid. ${ }^{10}$ Finally, the use of $i v$ supplementation may be viewed as an indirect indicator of pain where an anaesthetist responds to pain behaviour on the part of the patient. However, this measure lacks generalizability among anaesthetists since the criteria for supplementation is subjective and may vary among practitioners.

In view of the above, combined with the sample size calculations performed, the present findings strongly support the idea that there is no difference in analgesic efficacy between 25 and $50 \mu \mathrm{g}$ of epidural fentanyl during elective Caesarean section under epidural anaesthesia. One question that arises is whether these dose differences have any effect on postoperative pain. Research directed at this may help the clinician choose between the two doses. Furthermore, given the generally very low levels of pain recorded it would seem unnecessary ever to use doses higher than $50 \mu \mathrm{g}$ of epidural fentanyl, especially since higher doses have been associated with respiratory depression. ${ }^{6,8}$

There was no respiratory depression in this study, nor was there any pruritus. Drowsiness and nausea did not present major problems either and the dose of fentanyl used seemed to play no role in their decision. Some caution is needed in interpreting these findings. Compared to pain measurement, the assessment of nausea, pruritus and drowsiness have not been well studied. The sensitivity, reliability and validity of the measures used here have not been well documented. It is therefore not certain that the sample size used here was adequate to detect differences between groups on any of the above side effects.

It would certainly be in the interest of researchers in this area to develop and use appropriate measures of side effects just as the use of appropriate measures of pain would allow easier comparison of studies. Until this is done interpretation of studies on the use of epidural narcotics in obstetrics may be difficult.

In summary it appears that there is little to choose between doses of $25 \mu \mathrm{g}$ and $50 \mu \mathrm{g}$ of epidural fentanyl when used to improve the quality of analgesia for women having elective Caesarean sections under epidural anaesthesia. The low levels of pain seen in this study with the doses used also support the notion that higher doses of epidural fentanyl are probably unnecessary to provide optimal pain control. Finally, no relationship was observed between dose of epidural fentanyl and incidence of side effects. However, improved methods of assessing side effects are needed before any firm conclusions can be drawn.

\section{References}

1 Gaffud MP, Bansal P, Lawton C, Velasquez $N$, Watson $W A$. Surgical analgesia for cesarean delivery with epidural bupivacaine and fentanyl. Anesthesiology 1986; 65: 331-4.

2 Paech MJ, Westmore MD, Speirs HM. A double-blind comparison of epidural bupivacaine and bupivacainefentanyl for Caesarean section. Anaesth Intensive Care 1990; 18: 22-30.

3 King MJ, Bowden MI, Cooper GM. Epidural fentanyl and $0.5 \%$ bupivacaine for elective Caesarean section. Anaesthesia 1990; 45: 285-8.

4 Tessler MJ, Biehl DR, Naughler MA. Caesarean section with epidural carbonated lidocaine and fentanyl. Can J Anaesth 1988; 35: S110-1.

5 Preston PG, Rosen MA, Hughes SC, et al. Epidural anesthesia with fentanyl and lidocaine for cesarean section: maternal effects and neonatal outcome. Anesthesiology 1988; 68: 938-43.

6 Noble DW, Morrison LM, Brockway MS, McClure JH. Adrenaline, fentanyl or adrenaline and fentanyl as adjuncts to bupivacaine for extradural anaesthesia in elective Caesarean section. Br J Anaesth 1991; 66: 645-50.

7 Naulty JS, Datta S, Ostheimer G, Johnson MD, Burger $G A$. Epidural fentanyl for postcesarean delivery pain management. Anesthesiology 1985; 63: 694-8.

8 Brockway MS, Noble DW, Sharwood-Smith GH, McClure $J H$. Profound respiratory depression after extradural fentanyl. Br J Anaesth 1990; 64: 243-5.

9 Rosaeg OP, Suderman $V$, Yarnell $R W$. Early respiratory depression during Caesarean section following epidural meperidine. Can J Anaesth 1992; 39: 71-4.

10 Melzack $R$. The short-form McGill Pain Questionnaire. Pain 1987; 30: 191-7.

11 Huskisson EC. Visual analogue scales. In: Melzack R (Ed.). Pain Measurement and Assessment. New York: Raven Press, 1983: 33-7. 